\title{
Command and Control Planning and Teamwork: Exploring the Future
}

\author{
Bruce S. Sterling \\ Carl W. Lickteig \\ U.S. Army Research Institute \\ Armored Forces Research Unit \\ ATTN: TAPC-ARI-IK \\ Fort Knox, KY 40121-5620
}

Telephone: DSN 464-7046, Commercial (502) 624-7046

Email: sterling@ftknoxari-emh15.army.mil and lickteig@ftknoxari-emh15.army.mil

\begin{abstract}
Teams are increasingly important as organizations reengineer to meet information age conditions and objectives. This paper examines how participant ratings of command and control planning and observer assessments of teamwork were related in a series of futuristic missions conducted by the Mounted Maneuver Battlespace Lab at Fort Knox, KY. The exploratory results indicate that planning and teamwork may be closely related, particularly in the reengineered command and control organizations envisioned in the 2010+ timeframe.
\end{abstract}

\section{Introduction}

Teams are increasingly important in the effective functioning of information age organizations (Baker \& Salas, 1997). In private industry, project teams with members throughout the organization are often formed for product development (e.g., user-centered design/engineering). In the military, peacekeeping operations may require team members from combat arms, engineer and medical units, as well as non-government organizations such as the Red Cross to work together to successfully accomplish the mission.

As the importance of teams and team behaviors increases more research is focusing on the identification and determination of behavioral factors contributing to effective teamwork. As Ilgen (1999) points out, one research method involves examining behaviors that distinguish effective teams from less effective teams. This method has been used extensively by Navy researchers (e.g., Oser et al., 1989). Cannon-Bowers et al., (1995) provide a substantial list of behaviors that may help differentiate effective and ineffective teams. These behaviors include adaptability, shared situational awareness, performance monitoring and feedback, leadership/team management, interpersonal relations, coordination, communication, and decision-making.

An obvious question, however, is how do effective teams develop these teamwork behaviors? One possible answer is anticipation of team members' needs. Effective teams are able to "push" information and action to team members before it is needed versus team members having to "pull" information and actions from each other (Entin \& Serfaty, 1999). Underlying the notion of anticipation is the idea of a shared mental model of the team and the task. That is, because members understand the team task, and each other's task roles and functions, effective teams are able to anticipate what information and action other team members need.

There are many methods by which team members can acquire anticipation skills and shared mental models. These include cross training on others' jobs (Cannon-Bowers et al., 1998), direct training of team mental models (Duncan et al., 1996), and training feedback on teamwork behaviors (Stout et al., 1997). 
Team planning may be another important method for learning to anticipate other team members' needs. Team planning usually includes discussion and rehearsal of team tasks prior to performance. Moreover, team planning is often grounded by a specified task context and deadline that may help focus team members anticipation of own and others needs. For example, Stout et al., (1999) examined the effects of team planning on shared mental models, proactive providing of information, and performance errors in a low fidelity simulation called Gunship. Results showed better planning teams had more similar mental models, proactively provided more information, and made fewer errors under high workload. These results make sense, in that planning should involve discussing the mission, what is likely to happen, what different team members will do and what information they will need under various circumstances. Rehearsal may build a common model of the team and task conditions and result in better anticipation.

The present study focuses on team planning by examining the relationship between planning and teamwork behaviors. Unlike Stout et al, (1999), the findings reported here are based on the teamwork behaviors of an actual and intact team (i.e., squadron staff) operating in a high fidelity simulation environment.

\section{Method}

\subsection{Participants}

Participants were 14 active duty U.S. Army command and staff officers and NCOs at squadron level. They participated in a battle command reengineering experiment conducted by the Mounted Maneuver Battlespace Lab at Fort Knox, KY, in April 1999. Command and staff participants were equipped with futuristic command, control, communication and computers $\left(\mathrm{C}^{4}\right)$ envisioned for a 2010+ timeframe. As depicted in Figure 1, participants were organized into four nodes: Command 1 and 2, and Control 1 and 2. Command 1 and 2 included the battalion commander and deputy commander, respectively. Control 1 and 2 alternated between assisting control of the current mission and planning the next mission. Each node had an officer in charge, friendly operations officer or NCO, and an enemy operations officer or NCO. The control nodes also had a sensor NCO, responsible for operating the unmanned aerial vehicles attached to these nodes.

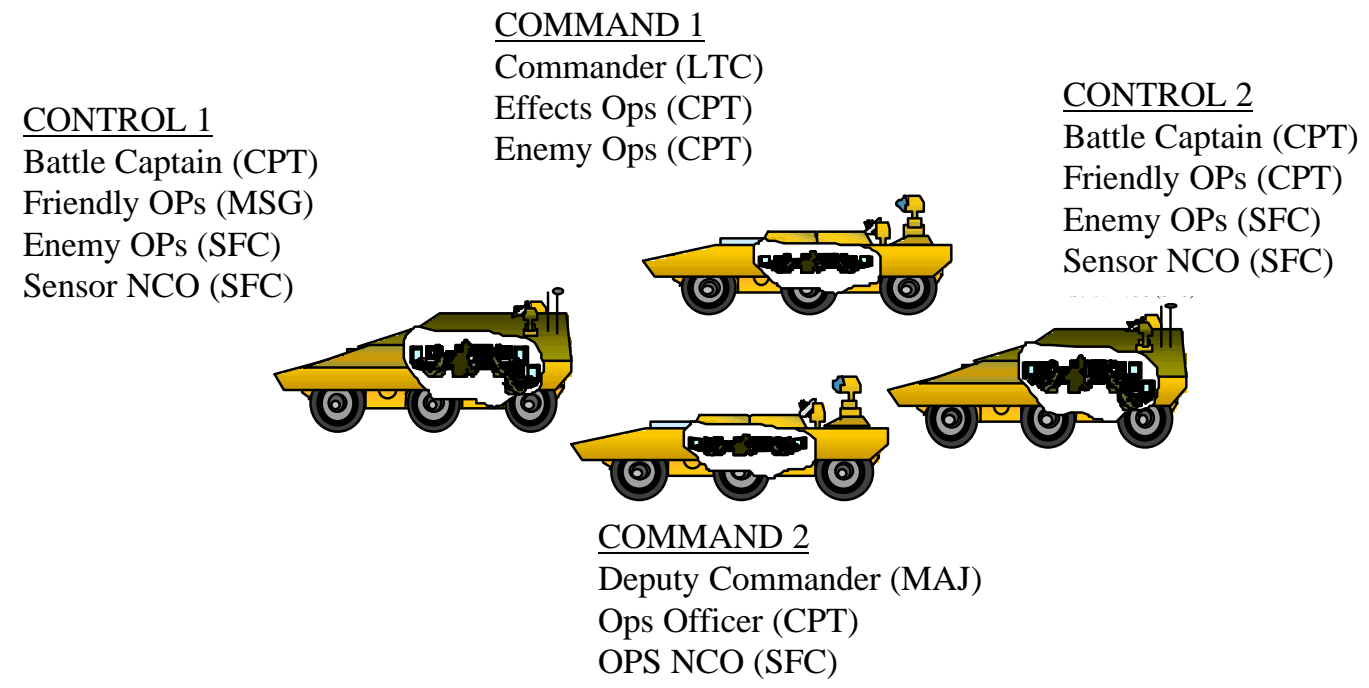

Figure 1. Reengineered battalion command group structure. 


\subsection{Measurement Instruments}

An Operations Planning Survey (OPS) was developed to assess the training designed to increase participant knowledge of other team members' roles and functions during tactical operations. The OPS items addressed how well individual command and staff members understood the mission and team members' roles and information requirements. Items included statements such as "I understood my role in the mission" and "I understood the information requirements of others." Overall, the OPS consisted of 11 such items. Participants responded to each item on a five-point scale, ranging from "Strongly Disagree" to "Strongly Agree."

A Teamwork Observation Form (TOF) was adapted from earlier research on naval command and control teams (Entin \& Serfaty 1999). The TOF included five sections on teamwork behaviors and an overall effectiveness rating. The behaviors were: communication; monitoring; back-up; coordination; and team orientation. A sample item under communication, for example, read: "To what extent were errors caused by inadequate within node communication?" Under back-up behaviors, a sample item read: "To what extent did node members anticipate the need to provide assistance to other nodes?" Overall, the TOF consisted of 14 such items with two to four items per behavioral category. Observers responded to each TOF item on a seven-point rating scale with behavioral anchors for the end points.

\subsection{Procedure}

The squadron executed one operational mission per day during the six days of evaluation. For each mission, the staff received an operations order from brigade headquarters and planned and executed the mission in coordination with supporting company level commanders. For the most part, company-level activities were performed via constructive simulation, as directed by the company commanders. Observers completed the TOF twice during each mission. An observer in each of the four staff nodes rated the overall node observed. Observers rotated among the nodes after each mission. Participants completed the OPS at the end of each mission.

\subsection{Analyses}

For planning, participants' scores were based on only five of the eleven OPS scale items. These five items assessed each participant's own planning versus the planning performed by other members of the participant's node or other nodes. It was assumed that ratings of own performance might provide more accurate and reliable data. Total scores for these five items were averaged over all members in each node for each mission. For teamwork behaviors, observers' TOF ratings on each behavioral category were averaged together by node by mission. Since both participant and observer data were collected on each of the six missions, a total of 24 data points (four nodes x six missions) for both planning and teamwork behaviors was possible. Preliminary review of this data based on scatter plots suggested a relationship between participants' perceptions of their planning and observers' ratings of teamwork.

To examine these relationships, a median split was performed on the data for the planning survey and each of the five teamwork behaviors. Medians were approximate because of the distribution of scores and the desire to use the scale midpoint for all the teamwork behaviors. Cross tabulations were generated comparing the planning scale data with each of the five teamwork behaviors. Since these data were not independent (i.e., each of the nodes accounted for six data points on each cross-tabulation), inferential statistics were not used. Note, that although the following Results section uses terms such as "higher" and "lower" ratings to describe the data, these terms in no way reflect statistically significant differences for these exploratory findings. 


\section{Results}

Based on median splits, cross tabulations were computed between planning and five teamwork behaviors: communication; monitoring; back-up; coordination; and team orientation. All five cross tabulations indicated a positive relationship between planning and teamwork behaviors. Overall, participant and observer ratings ranged from $71 \%-86 \%$ concurrence across the five cross tabulations examined.

The cross tabulation for planning and communication is shown in Table 1. Based on mediansplit comparisons, Table 1 indicates that participant planning and observer ratings of communication behaviors concurred $77 \%$ of the time (17 of 22 rating comparisons). These concurring ratings were evenly split on the above (9) and below (8) median ratings.

Table 1. Relation of Participant Planning and Observer Communication Ratings.

\begin{tabular}{|c|c|c|}
\hline \multicolumn{2}{|c|}{ Communication Ratings } \\
\hline $\begin{array}{c}\text { Participant } \\
\text { Planning Ratings }\end{array}$ & $\begin{array}{c}\text { Below } \\
\text { Midpoint }\end{array}$ & $\begin{array}{c}\text { At/Above } \\
\text { Midpoint }\end{array}$ \\
\hline \multirow{2}{*}{ Below Median } & $\mathrm{N}=8$ & $\mathrm{~N}=2$ \\
& $\%=80$ & $\%=20$ \\
& & \\
Above Median & $\mathrm{N}=3$ & $\mathrm{~N}=9$ \\
& $\%=25$ & $\%=75$ \\
\hline
\end{tabular}

Table 2. Relation of Participant Planning and Observer Monitoring Ratings.

\begin{tabular}{|c|c|c|}
\hline \multicolumn{2}{|c|}{} & \multicolumn{2}{c|}{$\begin{array}{c}\text { Observer } \\
\text { Monitoring Ratings }\end{array}$} \\
\hline $\begin{array}{c}\text { Participant } \\
\text { Planning Ratings }\end{array}$ & $\begin{array}{c}\text { Below } \\
\text { Midpoint }\end{array}$ & $\begin{array}{c}\text { At/Above } \\
\text { Midpoint }\end{array}$ \\
\hline \multirow{2}{*}{ Below Median } & $\mathrm{N}=7$ & $\mathrm{~N}=2$ \\
& $\%=77$ & $\%=23$ \\
Above Median & $\mathrm{N}=3$ & $\mathrm{~N}=9$ \\
& $\%=25$ & $\%=75$ \\
\hline
\end{tabular}

Results are quite similar in Table 2. Assessments of participant planning and observer monitoring agreed $76 \%$ of the time (16 of 21 rating comparisons). The agreement of the ratings was relatively evenly split on the above (9) and below (7) median ratings.

Tables 3 also shows good agreement between participant planning and observer ratings of backup behavior. Participant ratings of planning and observer ratings of backup behavior were consistent $81 \%$ of the time (17 of 21 rating comparisons). These consistent ratings were evenly split on above (8) and below (9) median ratings.

Table 3. Relation of Participant Planning and Observer Backup Ratings.

\begin{tabular}{|c|c|c|}
\hline \multicolumn{2}{|c|}{} & $\begin{array}{c}\text { Observer } \\
\text { Backup Ratings }\end{array}$ \\
\hline $\begin{array}{c}\text { Participant } \\
\text { Planning Ratings }\end{array}$ & $\begin{array}{c}\text { Below } \\
\text { Midpoint }\end{array}$ & $\begin{array}{c}\text { At/Above } \\
\text { Midpoint }\end{array}$ \\
\hline Below Median & $\mathrm{N}=9$ & $\mathrm{~N}=1$ \\
& $\%=90$ & $\%=10$ \\
Above Median & $\mathrm{N}=3$ & $\mathrm{~N}=8$ \\
& $\%=27$ & $\%=73$ \\
\hline
\end{tabular}

Table 4. Relation of Participant Planning and Observer Coordination Ratings.

\begin{tabular}{|c|c|c|}
\hline \multicolumn{2}{|c|}{} & \multicolumn{2}{c|}{$\begin{array}{c}\text { Observer } \\
\text { Coordination Ratings }\end{array}$} \\
\hline $\begin{array}{c}\text { Participant } \\
\text { Planning Ratings }\end{array}$ & $\begin{array}{c}\text { Below } \\
\text { Midpoint }\end{array}$ & $\begin{array}{c}\text { At/Above } \\
\text { Midpoint }\end{array}$ \\
\hline Below Median & $\mathrm{N}=9$ & $\mathrm{~N}=1$ \\
& $\%=90$ & $\%=10$ \\
Above Median & $\mathrm{N}=2$ & $\mathrm{~N}=10$ \\
& $\%=17$ & $\%=83$ \\
\hline
\end{tabular}


Results in Table 4 are quite similar to Table 3. Ratings of participant planning and observer coordination ratings were in accordance $86 \%$ of the time (19 of 22 rating comparisons). These mutual ratings were evenly split on the above (10) and below (9) the median.

Table 5. Relation of Participant Planning and Observer Team Orientation Ratings.

\begin{tabular}{|c|c|c|}
\hline \multicolumn{2}{|c|}{$\begin{array}{c}\text { Observer Team } \\
\text { Orientation Ratings }\end{array}$} \\
\hline $\begin{array}{c}\text { Participant } \\
\text { Planning Ratings }\end{array}$ & $\begin{array}{c}\text { Below } \\
\text { Midpoint }\end{array}$ & $\begin{array}{c}\text { At/Above } \\
\text { Midpoint }\end{array}$ \\
\hline \multirow{2}{*}{ Below Median } & $\mathrm{N}=6$ & $\mathrm{~N}=3$ \\
& $\%=67$ & $\%=33$ \\
& & $\mathrm{~N}=9$ \\
Above Median & $\mathrm{N}=3$ & $\%=75$ \\
\hline
\end{tabular}

Results in Table 5 shows the weakest level of agreement between participant and observer ratings. Participant ratings of planning and observer ratings of team orientation agreed $71 \%$ of the time (15 of 21 rating comparisons). These ratings were somewhat unevenly split on above (9) and below (6) median ratings.

Table 6 allows examination of observer and participant ratings on a node-by-node level and by Command versus Control node categories. Overall, the nodes rated most favorably on teamwork behaviors by the observers were the Command nodes.

Averaged across all five behaviors and the two node categories, observers' Table 6 mean (M) ratings of Command node teamwork $(\mathrm{M}=5.3)$ appear markedly more positive than their mean ratings of Control node teamwork $(\mathrm{M}=2.5)$. This pattern of higher Command node ratings by observers is consistent across each of the teamwork behaviors examined. In contrast, participant ratings of their own planning performance disclose a notable exception to a pattern of higher ratings for Command nodes. While Control 2 participants rated their planning lower than any other node, Control 1 participants rated their planning higher than any other node. Notably, this disconnect between observer and participant ratings for the Control 1 node account for many of the rating disagreements previously identified in the cross tabulation results, particularly the tabulations shown in the lower-left cells of Tables 1-5 that indicate higher ratings of planning and lower ratings of teamwork.

Table 6. Mean Observer Teamwork and Participant Planning Ratings by Node

\begin{tabular}{|l|c|c|c|c|c|c|}
\hline Node & \multicolumn{5}{|c|}{ Observer } & Participant \\
\hline & Commo & Monitor & Backup & Coord & $\begin{array}{l}\text { Team } \\
\text { Orient }\end{array}$ & Planning \\
\hline Command 1 & 5.28 & 5.10 & 4.47 & 4.80 & 4.88 & 4.29 \\
\hline Command 2 & 5.54 & 5.42 & 5.00 & 5.46 & 5.33 & 4.20 \\
\hline Control 1 & 2.90 & 2.50 & 2.20 & 2.56 & 2.71 & 4.31 \\
\hline Control 2 & 2.38 & 2.25 & 1.94 & 2.54 & 3.15 & 3.85 \\
\hline
\end{tabular}

Note . Commo $=$ Communication; Monitor $=$ Performance Monitoring Coord $=$ Coordination; and Team Orient $=$ Team Orientation. Scale midpoints were 4.00 on observer ratings and 3.00 on participant ratings.

\section{Discussion and Conclusions}

Overall, the findings generally indicate a consistent and positive relationship between team planning and teamwork. Participant ratings of their planning concurred with observer ratings of their teamwork behaviors between $71 \%-86 \%$ on the five behavioral categories examined. When participants perceived that there was better planning for a mission, observers generally assessed teamwork behaviors during that mission as better. This suggests a relationship between efficacy of mission planning and the degree of teamwork observed. Such a relationship is consistent with 
the literature on team anticipation cited earlier. That is, planning would provide team members with knowledge of what information or actions other team members might need, and under what conditions team members might need it, during the upcoming mission. This knowledge would allow team members to provide the information or action before it was requested, thus enhancing team performance.

However, potential differences in Command versus Control node ratings bear consideration. Higher participant and observer ratings were generally associated with the Command versus Control nodes, with the exception of participants' self-assessment of their planning in Control 1. Notably, Command 1 and 2 had the most senior and experienced personnel. The battalion commander, a Lieutenant Colonel, was in charge of Command 1, his enemy operations officer was the intelligence officer (S2) for the squadron, and his friendly operations officer was the squadron operations officer (S3). The squadron's Deputy Commander, a Major, was in charge of Command 2. Not only were these aforementioned officers some of the most experienced in the squadron, but as with nearly all units, duty position fills were hand-picked by the commander. In contrast, less senior and experienced officers, none exceeding the rank of Captain, served in Control 1 and 2.

Observer rating differences between Command and Control nodes might accurately reflect behavioral differences or a biasing expectation that more experienced team members exhibit better teamwork skills. Without more objective measures of participant and node performance (which were not available from this assessment), we cannot be certain whether the observers provided accurate measures of teamwork or whether the ratings were affected by the rank and position of the participants. One result that counters a biased observer explanation is the fact that on each of the five behavioral categories examined, the Deputy Commander's node, Command 2, received higher average ratings from observers than the Commander's, Command 1. This result suggests that something other than rank and position bias on the observers' part was occurring. In addition, the rotation of observers across nodes reduces observer bias interpretations.

One finding of special interest may be the comparatively large discrepancy between observer and participant ratings for the Control 1 node. As noted, observers consistently rated the teamwork behaviors of Control participants below the Command node participants. And the relatively low ratings that Control 2 participants provided on their planning performance appeared to concur with observer ratings. However, Control 1 participants' rated their planning performance higher than participants in any other node. Control 1's relatively high self-ratings contrasted sharply with observer ratings of their teamwork behaviors. A plausible interpretation is that less experienced and/or novice personnel are less able or likely to accurately assess their own performance, particularly more cognitive performance such as planning. If the self-ratings by Control 1 participants were inaccurate, as seemingly indicated by observer ratings of their behavior, more explicit feedback on planning and teamwork may have been needed. From a training perspective, this interpretation reinforces the need for extrinsic performance assessment and feedback, particularly during the earlier phases of training.

Overall, the results are promising in that they were obtained with an actual Army squadron commander and staff in a high fidelity simulation. Although exploratory, the findings suggest that planning and teamwork are closely related especially for a reengineered command and control organization, as examined. One area for future research is to experimentally manipulate the amount of planning performed by nodes or staffs, and examine its effect on teamwork behaviors. Another area is the need for more objective assessments of staff performance. Instrumentation of the $\mathrm{C}^{4}$ systems that will be used by future command and staff organizations might help provide more objective and precise automated measures of staff performance (Throne et al., 1999). In addition, automated measures might improve performance assessment and feedback, particularly during the earlier phases of training when trainees may not be able to accurately assess their own performance. Certainly, research with more and diverse teams is 
necessary to determine more precisely if and how better planning is associated with better teamwork.

\section{References}

Baker, D.P., \& Salas, E. (1997). Principles for measuring teamwork: A summary and look toward the future. In M.T. Brannick, E. Salas, \& Prince, C. (Eds.), Team performance assessment and measurement (pp. 331-355). Mahwah, NJ: Earlbaum.

Cannon-Bowers, J. A., Salas, E., Blickensderfer, E., \& Bowers, C. A. (1998). The impact of cross-training and workload on team functioning: A replication and extension of initial findings. Human Factors, 40, 92-101.

Cannon-Bowers, J. A., Tannenbaum, S. I., Salas, E., \& Volpe, C. E. (1995). Defining competencies and establishing team training requirements. In R. A. Guzzo \& E. Salas (Eds.), Team effectiveness and decision making in organizations (pp. 333-380). San Francisco: Jossey-Bass.

Duncan, P. C., Rouse, W. B., Johnston, J. H., Cannon-Bowers, J. A., Salas, E., \& Burns, J. (1996). Training teams working in complex systems: A mental model-based approach. Human/Technology Interaction in Complex Systems, 8, 173-231.

Entin, E. E., \& Serfaty, D. (1999). Adaptive team coordination. Human Factors, 41(2), 312-325.

Ilgen, D.R., (1999). Teams embedded in organizations. American Psychologist, 54(2), 129-139.

Oser, R., McCallum, G. A., Salas, E., \& Morgan, B. B. (1989). Toward a definition of teamwork: An analysis of critical team behaviors. Orlando, FL: Human Factors Division, Naval Training Systems Center.

Stout, R.J., Cannon-Bowers, J.A., Salas, E., \& Milanovich, D.M. (1999). Planning, shared mental models, and coordinated performance: An empirical link is established. Human Factors, 41(1), 61-71.

Stout, R.J, Salas, E., \& Fowlkes, J.E. (1997). Enhancing teamwork in complex environments through team training. Group Dynamics, 1(2), 169-182.

Throne, M. H., Deatz, R. C., Holden, W. T. Jr., Campbell, C. H., Sterling, B. S., \& Lickteig, C. W. (1999). Prototype staff training and evaluation methods for future forces (ARI Research Report 1745). Alexandria, VA: U.S. Army Research Institute for the Behavioral and Social Sciences. 